\title{
Analysis on Conservatory of Music and Musical Intangible Cultural Heritage
}

\author{
Chunhua Jiang
}

College of Arts Yanbian University, Yanji, Jilin, 133000, China

Keywords: conservatory of music; musical intangible cultural heritage; inheritance and protection

\begin{abstract}
Musical intangible cultural heritage is an important component of China's traditional music culture form, and has very important value in multinational life of China. Besides, it has far-reaching influence. When the conservatory of music carries out music education and inherits music culture in the new era, it should deeply cognize and understand the importance of inheritance and protection of musical intangible cultural heritage, actively explore the measures of inheritance and protection, strive to form the brand-new development trend and lay a solid foundation for modernization construction and development of music art and culture under the new era.
\end{abstract}

\section{Introduction}

Musical intangible cultural heritage is an important component of China's traditional national culture. Enhancing inheritance and protection of musical intangible cultural heritage has very important influence on protecting China's national culture and promoting the good development of national culture. Thus, it is required to explicitly cognize the importance of inheriting and protecting musical intangible cultural heritage, and give full play to the education functions of conservatory of music in the inheritance and protection activity during overall boosting construction and development of advanced socialist culture. Meanwhile, the conservatory of music should practically improve inheritance and protection effect for musical intangible cultural heritage and offer corresponding support and safeguard for construction of Chinese characteristic culture system.

\section{Conservatory of Music and Musical Intangible Cultural Heritage}

Through analysis of musical intangible cultural heritage, it is found that musical culture types involve intangible cultural heritage. In the practical research activity, it is found that musical intangible cultural heritage shows two relatively obvious features. It has nonindependence nature in the form. In the heritance and development process, musical intangible cultural heritage is often combined with other different forms of art types and shows the relationship of interdependent heritage and development. Kun Opera as the intangible cultural heritage of UN is an important manifestation pattern of national operas, and it is jointly formed by music, drama, performance and literature. Its comprehensiveness and integrality features are obvious. The survival state of musical intangible cultural heritage also shows obvious feature of original nature, which is embodied from traditional national and folk music forms. The features of regionalism and ethnic group are obvious, and they have close relations with integral cultural ecology. Based on the case study of Mongolian folk song in the aspects of the content, form and melody, the formation of music characteristics has close relations with Mongolian national character, life style and geographical environment.

Based on forming the preliminary cognition of musical intangible cultural heritage, systematic research and interpretation of basic conditions about the development of conservatory of music should be conducted in order to promote inheritance of musical intangible cultural heritage. The conservatory of music in Chain refers to successful experiences of western university system construction and planning, and the subjects are classified into fundamental engineering of system construction. Corresponding achievements have been achieved in the construction aspect. Through 
the analysis on construction and development of music colleges, we can see that the conservatory of music can be roughly classified into three types: music department in the comprehensive university, music department in the academy of arts, and independent conservatory of music. Besides, based on systematic research, we can find that subject belonging of conservatory of music involves literature, musicology, art and music education. The conservatory of music plays a great role in professional music talent training and greatly promotes inheritance and development of traditional conservatory of music.

\section{Contradictions in Inheritance and Development of Musical Intangible Cultural Heritage}

Through the systematic analysis and planning of conservatory of music and musical intangible cultural heritage, we can see that, two levels of contradictions appear during promoting heritage and development of musical intangible cultural heritage. Only when the two levels of contradictions are handled and analyzed can the important cognition of musical intangible cultural heritage form. Further, cultural inheritance effect can be enhanced obviously. On the basis of improving professional music talent training effect, the brand-new development effect of cultural inheritance can be promoted. Next, the contradictions are analyzed in detail as follows to provide theoretical reference for heritage and development of musical intangible cultural heritage under the support of conservatory of music.

The first level of contradiction is that single subject basis in conservatory of music and musical intangible cultural heritage have obvious nonindependence contradiction in the form. During studying musical intangible cultural heritage, the famous music anthropologists explicitly propose research contents are divided into three important levels: impression, behavior and concept. Many researchers take this as the starting point of research, analyze music theory construction and the formation of multiple thoughts and explicitly cognize the multiplicity feature of musical culture in the aspects of role, essence, mode and social power. Besides, such multiplicity feature can be manifested from the perspective of human ecology. At the level of structure, it shows the changes from microcosmic system to macroscopic system, and gradually facilitates the multiple architecture of musical and social culture. The formation of such thinking mode and enrichment of research theories place music in corresponding cultural background for interpretation to certain degree so as to achieve research and analysis of music art form from multiple different thinking forms ${ }^{[1]}$. The conservatory of music is often influenced by western experience in the development process, regard single subject as the foundation and hopes to handle technical problems involved in music, such as focusing education emphasis on performance technique and composition technique. But, musical intangible cultural heritage is often embodied from the perspective of traditional national and folk music form. The complete technical system similar to the western countries fails to form in the development process, and technical content is low. So, the conservatory of music has certain disadvantages in heritage and development of musical intangible cultural heritage, and obvious inheritance contradiction will form, which will seriously hinder the promotion of inheritance effect and also affect enhancement of talent training effect.

The second level of contradiction is the contradiction between urbanism of conservatory of music and original nature of musical intangible cultural heritage. During studying musical intangible cultural heritage, social musicologists consider that as national and folk traditional music culture form, musical intangible cultural heritage presents certain community character in the inheritance and development process. In other words, the common interest, common social system and structure as well as the ecological environment and geographical environment get involved ${ }^{[2]}$. In recent years, these social living spaces are squeezed by cities and even destroyed, and the important features also gradually disappear in the process of overall driving urbanization construction. Even, musical intangible cultural heritage loses the living environment in the development process. Thus, it is required to actively explore the construction of symbiotic environment to ensure the formation of 
ecological system in inheritance and development of musical intangible cultural heritage. In other words, if inheritance and development of musical intangible cultural heritage break away from original living space, the nature will change obviously, thus leading to bad influence on inheritance and development effect. Thus, some contradictions will be inevitably encountered by the conservatory of music with obvious urbanism feature inherits and protects musical intangible cultural heritage. How to restore the living environment of musical intangible cultural heritage? This should be mainly concerned by the conservatory of music in heritage and development of musical intangible cultural heritage.

\section{Measures to Effectively Inherit and Protect Musical Intangible Cultural Heritage with the Force of Conservatory of Music}

The active exploration of heritage and protection of musical intangible cultural heritage not just needs to depend on the force of conservatory of music. Meanwhile, the form of joint attention, effort and participation should form in the protection practice so as to ensure inheritance and protection effect of musical intangible cultural heritage. Then, the conservatory of music can give play to its value to the largest extent, and the new development achievements can be promoted in the new era.

\subsection{To promote exertion of static protection function of conservatory of music}

When the force of conservatory of music is used for inheritance and protection of musical intangible cultural heritage, the measures of static protection should be actively explored to make sure inheritance and protection can gain the brand-new development achievement in the new era. Based on current development conditions, due to the violent impact in inheritance and protection of musical intangible cultural heritage, the living environment of musical intangible cultural heritage gradually changes and even dies out. To achieve favorable inheritance effect and make it inherited in the fundamental statistic sound or audiovisual way, all conservatories of music should specify the duties in the development process, enhance attention to protection of local musical intangible cultural heritage. In order to further improve practical effect of statistic protection and inheritance, the special institution may be set up to take charge of music culture protection, collection and research and facilitate inheritance and protection of intangible cultural heritage. For example, Xinghai Conservatory of Music and Wuhan Conservatory of Music constructed Lingnan music research center and Taoism music research center to take charge of local national music research and static culture inheritance. Good achievements have been achieved. In the previous research practice, the researches on national and folk music, and musical intangible cultural heritage coincide obviously. So in order to construct a more complete research system, the special department should be established to construct the scientific research system and ensure improvement of comprehensive research level. Under the condition of promoting effective connection between protection work of conservatory of music and inheritance of musical intangible cultural heritage, music colleges in different places can actively try to explore construction of folk music museum and explore construction of folk music eco-circle so as to offer favorable support for sampling and protection of original music and speed up modernization construction and development of inheritance and protection of national and folk music.

\subsection{To enhance training of intangible cultural heritage protection inheritors}

In order to give full play to the important education strength of conservatory of music, during exploring the protection of musical intangible cultural heritage, the detailed conditions should be combined to carry out systematic research and analysis, strive to build a professional talent training base and cultivate high-quality talents for protection and inheritance of musical intangible cultural heritage. In practical work, the brand-new talent training standards should be set based on inheritance and protection of musical intangible cultural heritage. Meanwhile, the talent training institutions should be improved systematically to guarantee the analysis of the demand for musical intangible cultural heritage talents from multiple perspectives. Besides, relatively scientific talent training 
working system should be set to promote overall implementation of talent training work. During organizing talent training, on the one hand, professional knowledge and ability cultivation should be concerned to make sure the talents are familiar with laws, rules and regulations of musical intangible cultural heritage as well as professional technical ability. On the other hand, it is required to intensify talents' protection and management awareness for musical intangible cultural heritage, let them cognize the importance of protection and inheritance work, and make them consciously participate in cultural heritage protection and inheritance practice so as to create conditions for sound development of musical intangible cultural heritage in the original environment. Only when the importance role of conservatory of music in talent training is exerted can the prominent effect be achieved in the protection of musical intangible cultural heritage.

\subsection{To actively explore propaganda for protection and inheritance of musical intangible cultural heritage}

Propaganda work is especially important during organizing the protection of musical intangible cultural heritage. The conservatory of music should comprehensively analyze protection and inheritance demand of musical intangible cultural heritage and combine current conditions to actively carry out propaganda and education activities so that more people can cognize the importance of protection and inheritance of musical intangible cultural heritage, take active part in protection and inheritance work, and improve autonomous inheritance awareness. In this way, the better effect can be achieved in the protection and inheritance of musical intangible cultural heritage.

\section{Summary}

In conclusion, protection and inheritance of musical intangible cultural heritage is a project with strong systematicness. The conservatory of music needs long-term effects. Only when the conservatory of music cognizes the importance of protection and inheritance of musical intangible cultural heritage and enhance attention to protection and inheritance in talent training work can the important role of school education be really exerted. Meanwhile, remarkable development achievements can be gained in protection and inheritance of musical intangible cultural heritage. As well, the solid foundation can be laid to develop talent training work of conservatory of music and construct music culture system with national features.

\section{Acknowledgement}

This research was financially supported by the Humanistic and Social Science Fund Program of Yanbian University. Comparative Study on Diachronism of Chinese Korean Nationality and Korean "Pungmul" in the Context of Cross-border Nationality. (ND2017010).

\section{References}

[1] Zhao Jun, Protection and Inheritance - 2015 "National Intangible Cultural Heritage Protection and Research Work Conference” in Central Conservatory of Music, Journal of Central Conservatory of Music, 2016(1):157-158.

[2] Ren Fei, Jiang Xiaoting, The Research of Musical Non-material Cultural Heritage Protection Practice in Jiangxi Province After the Founding of the PRC, Journal of Qiqihar University (Philosophy and Social Science), 2017(6):139-141.

[3] Wu Chunwei, Education and Inheritance of Non-material Musical Cultural Heritage, Journal of Changchun Normal University, 016, 35(4):180-182.

[4] Zhou Yun, On The Third Way for Protection and Inheritance of Intangible Cultural Heritage Expansion of College Traditional Music Teaching Function, The New Voice of Yue Fu, 
2016(3):105-108.

[5] Tang Dalin, Study on Music - "Intangible Cultural Heritage” under the View of Composing Technique Theory - Case Study of “Shengzhou Chui Da”, Music Creation, 2017(6):143-145. 